\title{
LIVING MUSEUM MUSTIKA RASA NUSANTARA DI PEKOJAN JAKARTA UTARA
}

\author{
Jeremy Vincent ${ }^{1)}$, Suwardana Winata ${ }^{2)}$ \\ ${ }^{1)}$ Program Studi S1 Arsitektur, Fakultas Teknik, Universitas Tarumanagara, jeremy.vincent1212@gmail.com \\ 2) Program Studi S1 Arsitektur, Fakultas Teknik, Universitas Tarumanagara, danarsitek@gmail.com
}

Masuk: 04-07-2021, revisi: 31-07-2021, diterima untuk diterbitkan: 23-10-2021

\begin{abstract}
Abstrak
Museum adalah tempat untuk menyimpan, mengamankan, serta merawat koleksi sebuan benda yang memiliki nilai kebudayaan. Sehingga museum memiliki fungsi sebagai tempat menyediakan informasi suatu kebudayaan untuk edukasi dan penelitian masyarakat. Namun kebanyakan koleksi benda di suatu meseum adalah benda mati hanya memiliki interaksi satu arah, sehingga cenderung kurang diminati oleh masyarakat karena terasa bosan dan monoton. Hal ini tentu menjadi tantangan tersendiri bila ingin membuat museum yang memilih tema kuliner sebagai ekshibisinya, karena kegiatan seperti memasak, penataan makanan, hingga cara memakanya adalah kegiatan praktek yang sulit sekali dibuat lisan. Bahkan bila hanya dibuat dokumentasi video, pengalaman akan kegiatan praktek itu akan sulit dirasakan, karena hanya video sendiri adalah dokumentasi yang hanya bisa dilihat, dan berinteraksi satu arah saja. Sehingga tercetuslah suatu konsep yang bernama living museum/museum hidup, suatu jenis museum yang mengajak pengunjung untuk berinteraksi dan merasakan kejadian suatu periode kebudayaan dua arah dengan benda yang menjadi koleksinya.
\end{abstract}

Kata kunci: budaya ; cara masak ; keanekaragaman ; living museum

\begin{abstract}
A museum is a place to store, and maintain a collection of objects that have cultural value. The museum has a function as a place to provide information on a culture for public education and research. However, most of the collections of objects in a museum are inanimate objects that only have one-way interaction, so they tend to be less attractive to the public because they feel bored and monotonous. This challenge begin with how the architecture can accommodates all museum activities, but in the live versions. Even if only video documentation is made, the experience of the practical activities will be felt, because only the video itself is a documentation that can only be viewed and interacted in one direction only. Thus, a concept called a living museum was born, a type of museum that invites visitors to interact and feel the events of a two-way cultural period with the objects that are in their collection.
\end{abstract}

Keywords: culture ; cooking ; diversity ; living museum

\section{PENDAHULUAN}

\section{Latar Belakang}

Indonesia adalah negara luas yang memiliki dengan 300 kelompok etnis dengan 1.340 suku bangsa yang memiliki berbagai agama, budaya, dan termasuk makanannya. Setiap suku dan etnis memiliki ciri khas makananya tersendiri, bahkan, masakan yang ada di Indonesia kebanyakan telah terasimilasi dengan kebudaan luar. Mulai dari era Kerajaan Hindu-Buddha, era Kerajaan Islam, hingga masa perdagangan di era kolonialisasi telah membuat makanan di Indonesia menjadi bereaneka ragam dan saling bercampur aduk. Misalnya adonan tepung dan roti dari India dan Eropa, Mi dari Cina, bahkan rempah-rempah dari Brazil, India, dan Afrika pun terbawa hingga kesini dan telah menjadi salah satu bahan makanan yang sangat umum dijumpai di kuliner Indonesia. Bahkan pada saat tahun 60an, Presiden Ir.Soekarno membuat suatu proyek bernama buku masakan nasional "Mustika Rasa" yang memuat 6000 resep dari seluruh indonesia. Namun, dalam buku itu disebutkan bahwa hanya 2 resep terpilih dari berbagai daerah, dan itu pun masih belum menjangkau semuanya. 
Tentu proses pembuatan buku "Mustika Rasa" selain sebagai satu dari proses dokumentasi kuliner sebagai kekayaan bangsa, agar bagaimana mereka yang berbeda suku dapat memasak dan mencoba masakan dari suku lainya. Hal ini secara tidak langsung terbukti dengan tren wisata yang selain mengejar keindahan alam sebagai destinasi wisata, kuliner khas suatu daerah menjadi satu hal yang dicari oleh wisatawan. Bahkan di beberapa tempat seperti Gudeg Mbah Lindu di Yogya, dan Depot Bu Rudy di Surabaya, pengujung dapat mengenal dan berkenalan dengan dengan pemilik atau juru masaknya. Hal ini memperkuat bahwa makanan selain untuk dimakan, juga menjadi wadah untuk berinteraksi, meskipun memiliki perbedaan suku, ras, budaya, dan agama.

\section{Rumusan Masalah}

a. Mengenalkan keanekragaman kebudayaan Indonesia yang melalui makanan sebagai bagian dari kebudayaan.

b. Menjadikan makanan, mulai dari proses masak, hingga penyajianya sebagai interaksi antara pengunjung dengan juru masak, sekaligus sebagai wada edukasi untuk pembelajaran.

\section{Tujuan}

a. Menciptakan wadah edukasi dan interaksi keanekaragaman kebudayaan yang ada di Indonesia melalui makanan, cara memasak, dan cara makan suatu makanan.

b. Membuat wadah koleksi masakan di indonesia, proses praktek seperti cara memasak yang dilakukan secara langsung dan menjadi daya tarik pengunjung untuk mengenal, dan berinteraksi.

\section{METODE}

Pengumpulan data dilakukan melalui studi literatur seperti buku / e-book, publikasi jurnal, dan berita sebagai dasar membangun landasan teori dalam merancang proyek ini. Adapun data yang dikumpulkan akan diproses untuk menentukan usulan program bangunan, sirkulasi pada bangunan, pembagian zona bangunan, serta tidak lupa hubungan kajian Iliteratur pada proses peracangan.

\section{KAJIAN LITERATUR}

Menurut buku The Modern Living Museum: Some Reflections and Experiences (UNESCO,1975) Living Museum adalah suatu konsep museum yang mereplika kegiatan suatu periode waktu atau kegiatan di masa lampau. Tujuan dari museum ini adalah memberi pengalaman interaksi langsung, serta interpretasi suatu kejadian yang ingin diceritakan melalui. Interaksi ini penting mengingat bila di museum konvensional biasanya, karya atau objek benda mati tertulis cenderung terbatas dalam penyampaian informasi . Koleksi benda mati ini hanya memberikan komunikasi satu arah yang membuatnya tampak membosankan. Sehingga suatu Living Museum harus mereplika suatu pengalaman kondisi budaya, lingkungan alam, periode sejarah kedalam suatu interaksi yang dapat dirasakan oleh pengunjung secara kreatif, menarik, dan edukatif.

Objek yang di interpretasikan biasanya berupa pegawai berkostum yang mereprentasikan sejarah yang ingin diceritakan sebagai narasumber sudut pandang orang pertama. Si orang pertama ini akan melakukan kegiatan yang dapat mewakili suatu periode kebudayaan yang ingin diceritakan. Kegiatan ini akan mengajak pengunjung untuk merasakan secara dan berinteraksi secara langsung, sehingga penyampaian informasi dan transfer kebudayaan dapat dirasakan oleh pengunjung. 


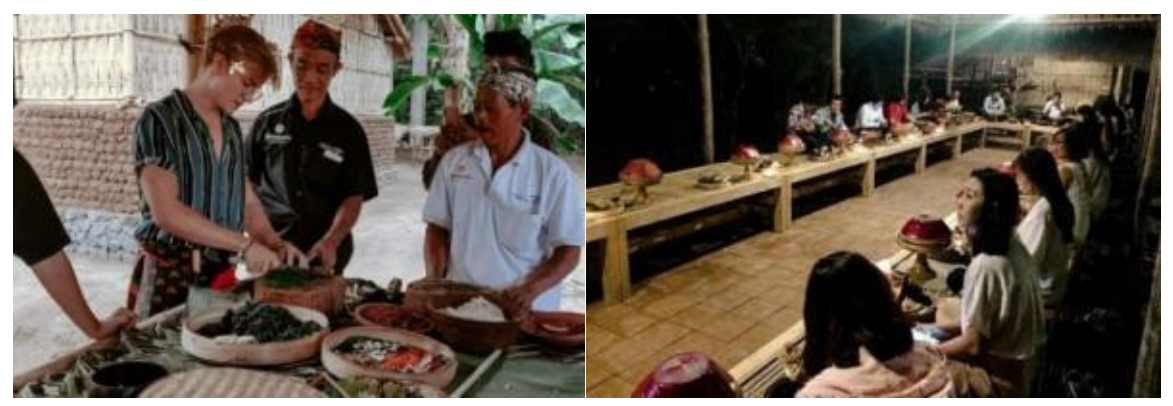

Gambar 1. Living Museum yang Mereplikasi Penyampaian Kegiatan Memasak, dan Cara Makannya. sehingga Terdapat Interaksi dan Pengenalan Kebudayaan pada Proses Memasak Sumber: America Alliance Museum, 2021

Menurut buku The Practice of Everyday Life Living and Cooking (Michel de Certeau,1984) Kegiatan memasak meskipun terlihat sederha, ternyata terdapat sekumpulan kisah dan kegiatan yang cukup rumit didalamnya. Memasak adalah melakukan proses imajinasi akan bentuk, dan rasa agar dapat dinikmati dan diterima oleh masyarakat yang mekananya. Terdapat banyak proses seperti mencampur bahan-bahan, teknik mengolahnya, hingga melakukan eksperimen agar rasa makanan tersebut dapat sesuai apa yang juru masak inginkan, serta dapat diterima oleh mereka yang makan. Kemudian karena perbedaan kondisi geografis, maka bahan-bahan, teknik memasak, hingga rasa suatu makanan akan berbeda bergantung dimana makanan itu diciptakan. Proses dan hasil dari memasak seringkali menjadi ciri khas dan menjadi bagian dari suatu kebudayaan karena perbedaan tersebut.

Kemudian tidak hanya itu, makanan dapat menjadi wadah untuk mengenal dan merekatkan hubungan baik pada masyarakat lokal, seperti sesama pemilik toko, atau dengan pelanggannya. Setelah bekerja, manusia akan beristirahat dan makan adalah salah satu hal yang dilakukan untuk mengembalikan energi yang hilang. Pada saat makan ini lah, interaksi terjadi karena selain pemenuhan perut, manusia adalah mahluk sosial yang membutuhkan komunikasi untuk memenuh kebutuhan sosialnya. Apalagi proses memesan dan menunggu makanan memerlukan interaksi, bahkan terkadang sembari menunggu, interaksi dan basa basi secara alami akan terjadi untuk menghindari rasa bosan.

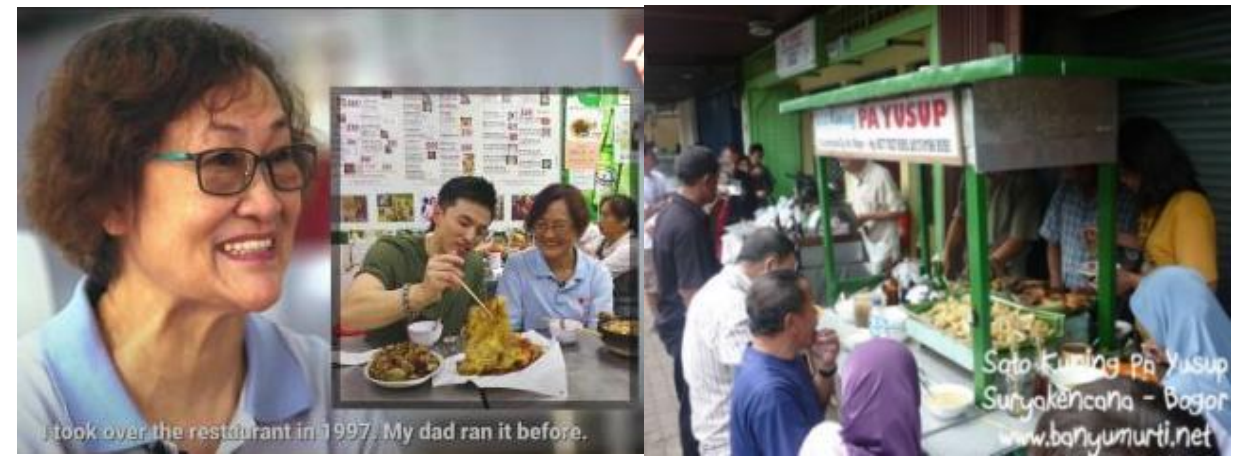

Gambar 2. Makanan Menjadi Wadah untuk Berinteraksi Antar Golongan Sumber: buzzfeed, 2019 ; banyumurti.net ; 2011 ; asumsi ; 2019

\section{DISKUSI}

Karena dapur adalah proses yang membicarakan keseharian, maka pada buku Peta Metode Desain karya Agustinus Suntanto, terdapat metode yang mempelajari keseharian sebagai pedoman untuk proses perancangan. Metode keseharian sendiri membangun pendekatan dialogis pada partisipasi manusia dan masyarakat, yang akan menciptakan suatu realitas melalui sebuah narasi yang dibangun berdasarkan kegiatan keseharian suatu masyarakat. Hal 
ini sejalan dengan kisah dalam dapur sebagai wujud keseharian yang diceritakan pada buku The Practice of Everyday Life Living and Cooking (Michel de Certeau, 1984).

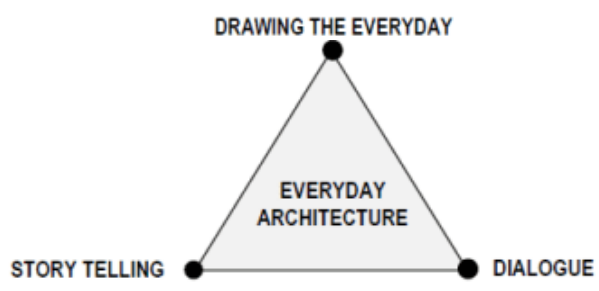

Gambar 3. Diagram Taktik dalam Membaca Keseharian Sumber: America Alliance Museum, 2021

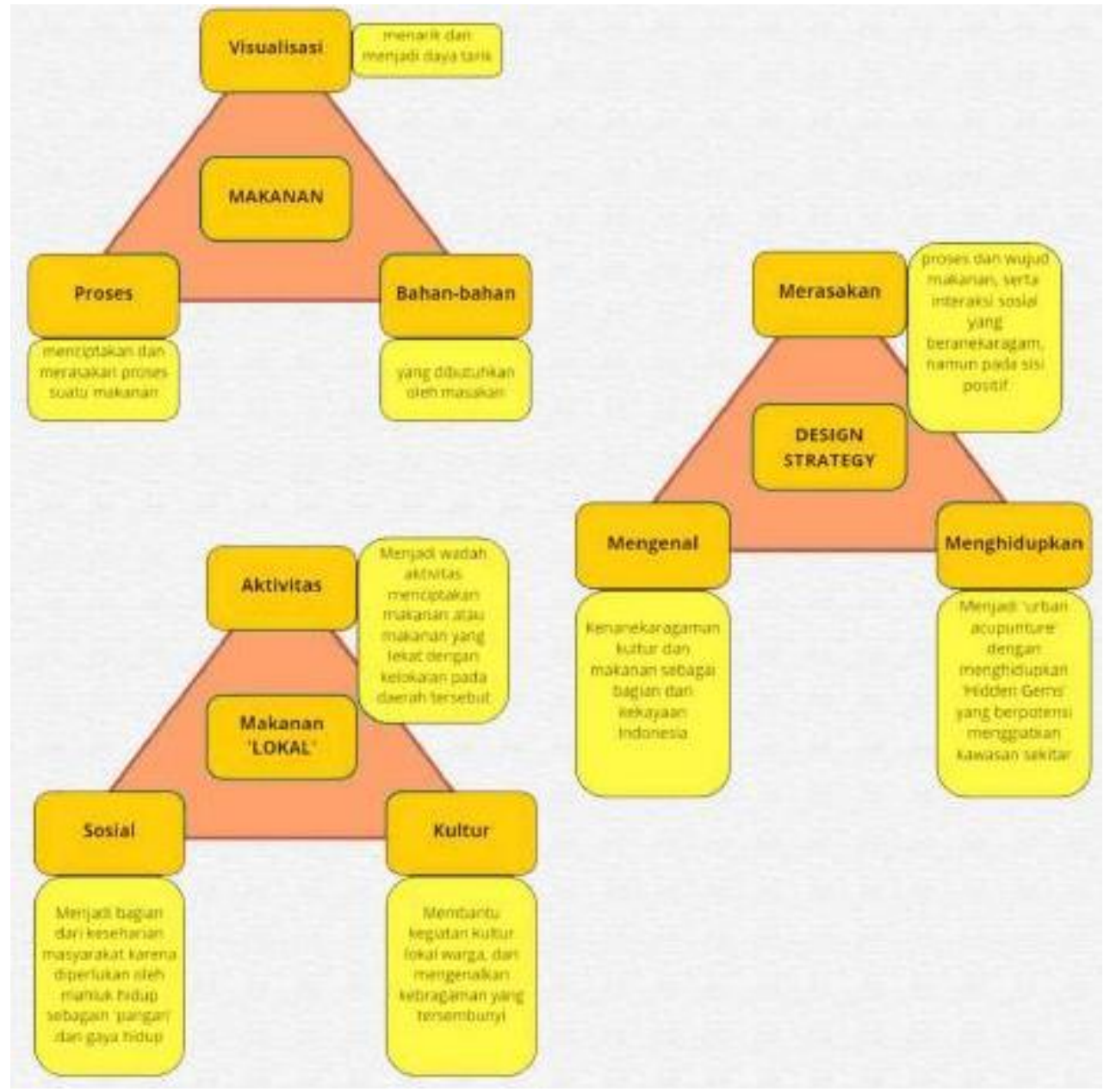

Gambar 4. Diagram Taktik yang Akan Dilakukan pada Proses Merancang Sumber: Penulis, 2021

\section{HASIL}




\section{Koleksi Museum}

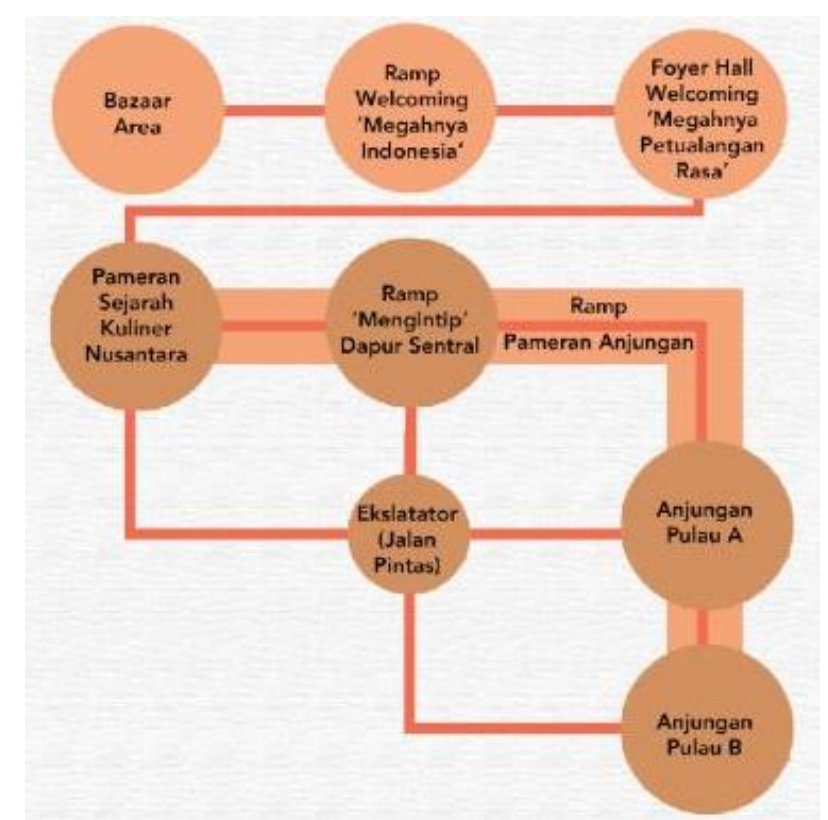

Gambar 5. Sirkulasi dan Sequence di Dalam Bangunan Sumber: Penulis, 2021

Pembagian Koleksi Museum akan dibagi kedalam beberapa anjungan yang mendemonstrasikan proses memasaknya. Pembagian setiap anjungan ini berdasarkan pulaupulau yang ada di Indonesia, yakni Sumatra, Jawa, Kalimantan, Sulawesi, Papua, Kepulauan Selatan (Bali, NTT, NTB), dan Kepulauan Utara (Maluku). Pembagian ini didasarkan karena berbagai kuliner tersebut karena banyak sekali kuliner yang berbeda provinsi di suatu pulau, ternyata memiliki kemiripan dan hanya memiliki perbedaan nama atau bahan baku minornya saja. Lalu terdapat anjungan non-halal agar pengunjung tetap dapat mencicipi serta melihat proses memasak tanpa mengganggu proses tersebut di anjungan lainnya yang menyediakan makanan halal, melihat sebagian besar masyarakat Indonesia sebagian besar beragama muslim.

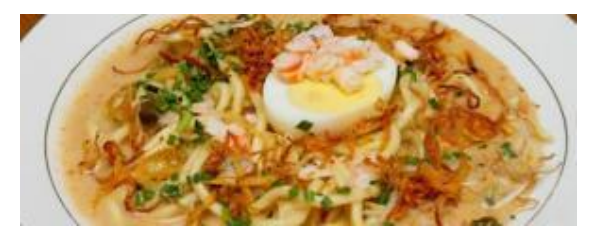

Gambar 6. Mie Celor atau Mie Telur yang menjadi masakan khas Jambi dan Sumatera Selatan Sumber: idn.times, 2021

Setiap koleksi museum akan saling bersambung dengan menggunakan ramp, agar pengunjung dapat merasakan pengalaman bergerak mengelilingi bangunan seperti yang diterapkan di Museum Guggenheim, Museum Mercedes Benz, dan Museum Nasional Hanoi. Kemudian tidak hanya pengalaman ruang, penggunaan ramp agar ramah sirkulasi ramah untuk anakanak, orang tua, dan kaum yang menggunakan kursi roda untuk membantu mobilitasnya, sehingga mereka semua dapat mengunjungi museum ini. 


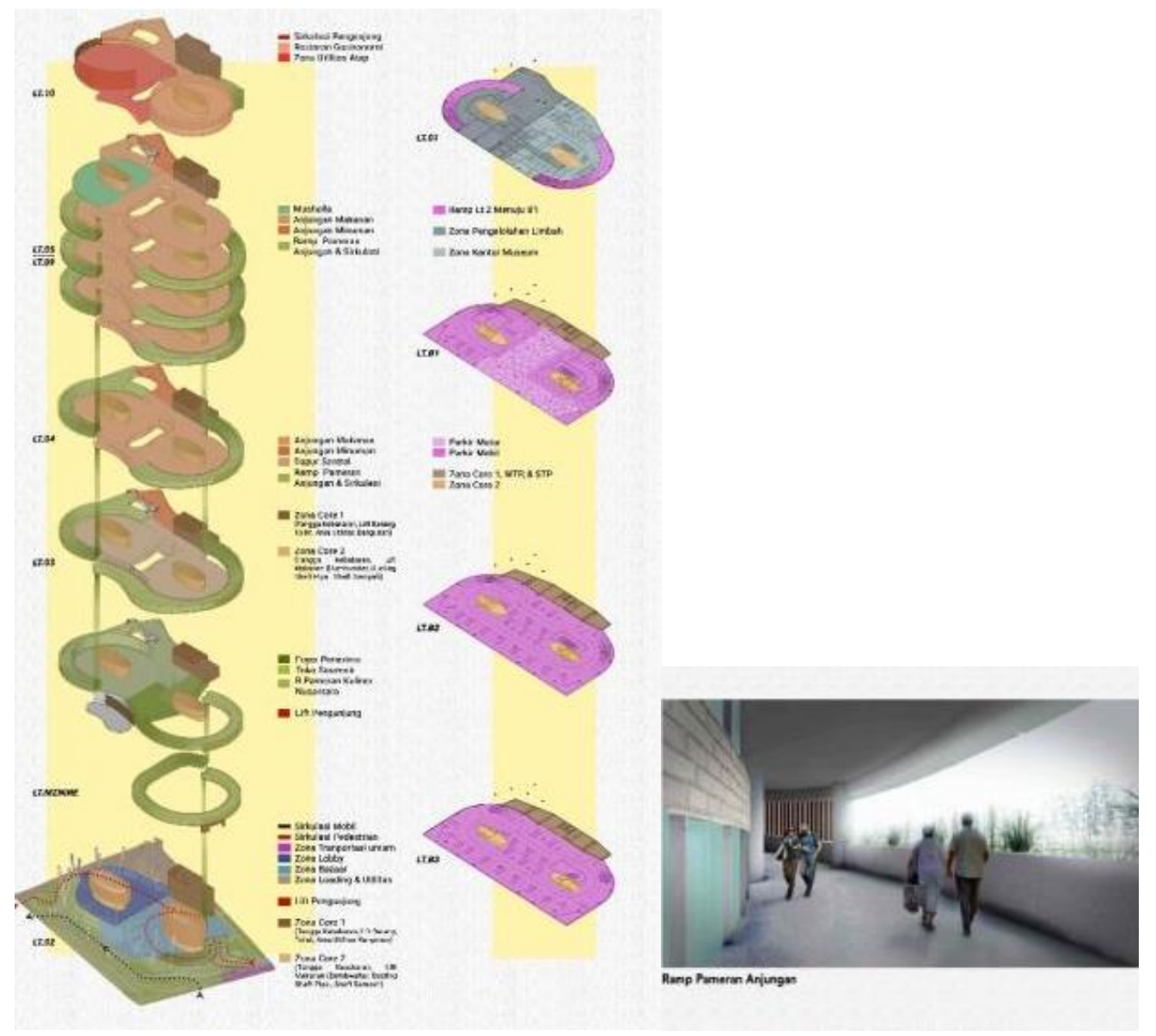

Gambar 7. Penggunaan Ramp di Dalam Bangunan.

Sumber: Penulis, 2021

Setiap proses memasak masakan ini dilakukan di Dapur Sentral untuk proses bahan makanan hingga setengah jadi, dan Dapur Exhibit yang menunjukan cara memasak suatu makanan. Dapur Sentral mengolah bahan makanan yang kurang atraktif seperti memotong sayur, daging, dan beberapa bahan makanan hingga setengah jadi. Kemudian bahan makanan setengah jadi ini akan dibawa dengan dumbwaiter menuju dapur ekshibisi pada setiap anjungan. Selain itu posisi Ruang Penyimpan Daging dan Sayur juga berkolasi di Dapur Sentral agar kontrol bahan makanan dapat sekaligus terjaga.

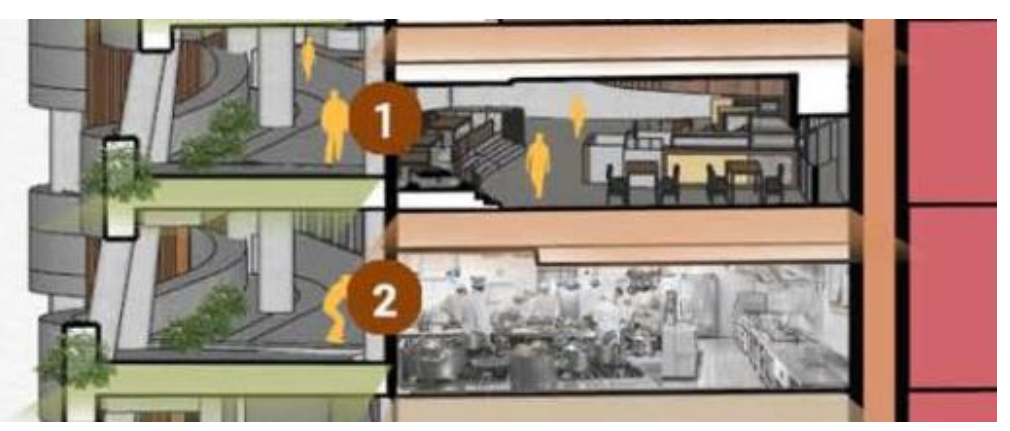

Gambar 8. Dapur Sentral di Nomor 2, dan Dapur Exhibit di Setiap Anjungan pada Nomor 1 Sumber: idn.times, 2021

Pada area Dapur Ekshibisi, posisi tempat makan berada di dekat dapur agar interaksi pengunjung dan tukang masak dapat lebih mudah terjadi. Model Dapur Exhibit 1 khusus untuk area bakar, sementara Modul Dapur Exhibit 3 untuk suasana makan-makan seperti di jalanan. 
Beberapa makanan seperti Pecel Semarang dan Gultik lebih nikmat, serta lebih akrab bersosialisasi pada suasana seperti itu. Kemudian pada Zona Kue Tradisional mengajak pengunjung untuk latihan membuat kue tradisional, modul kuenya. Modul Demo memasak untuk live cooking.

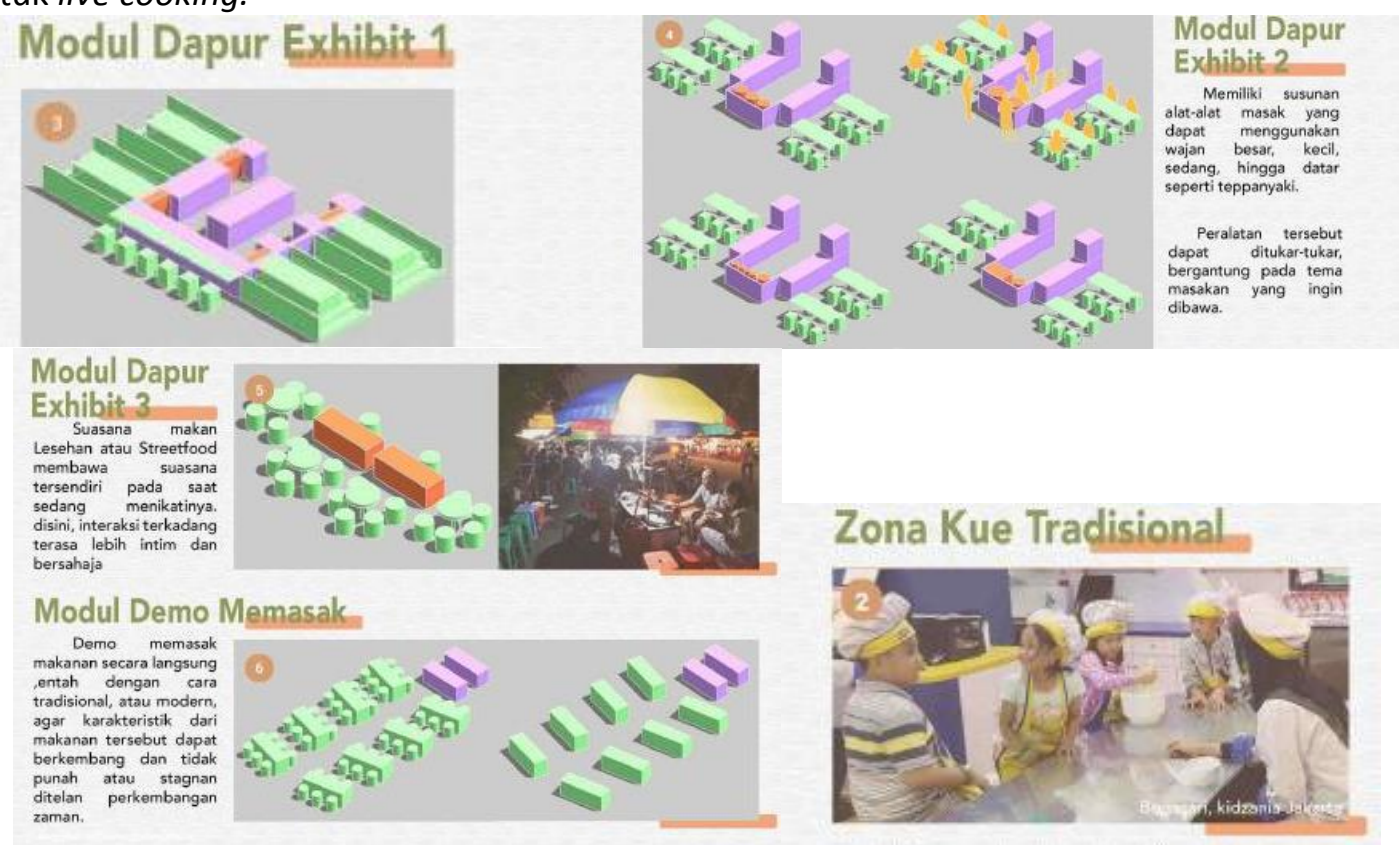

Gambar 9. Beberapa Dapur Eksibisi pada Setiap Anjungan. Sumber: Penulis, 2021

Kemudian pada area anjungan terdapat zona meja lesehan untuk tempat makan lebih besar untuk berkumpul, atau ingin merasakan pesta makan-makan adat seperti pesta makan Adat Sunda dan Adat Batak. Posisi pengunjung pada saat duduk lesehan akan sejajar dengan pengunjung yang sedang makan di dekat dapur eksibisi agar sejajar. Posisi ini seakan-akan mengisyaratkan bahwa apapun perbedaan posisi makanya, manusia seharusnya sejajar dan seimbang.

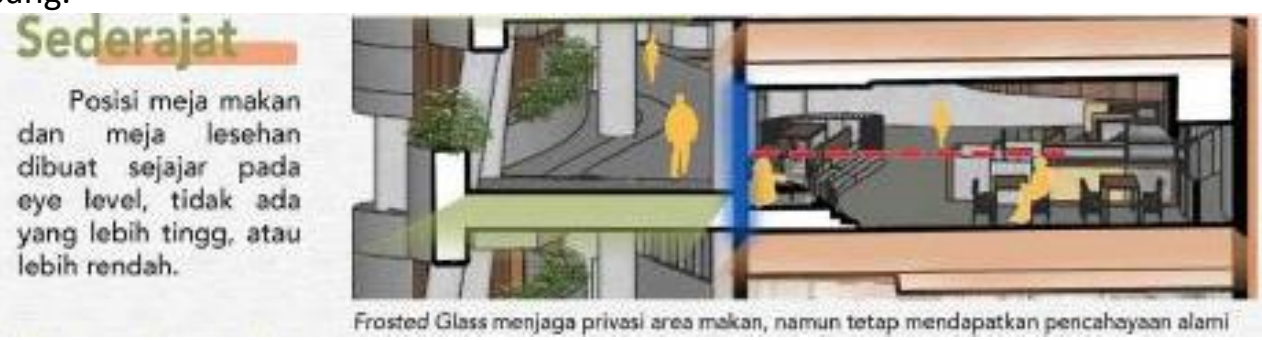

Gambar 10. Area Lesehan Setiap Anjungan.

Sumber: Penulis, 2021

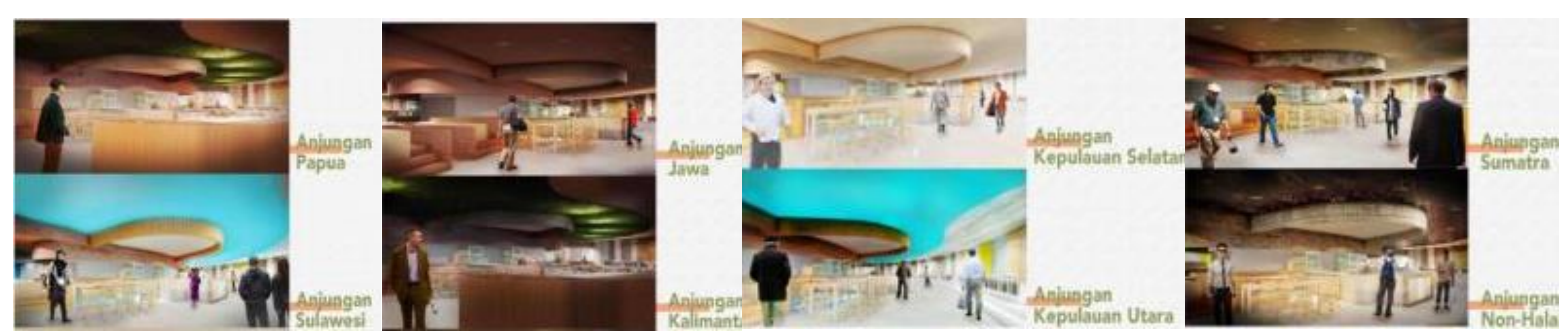

Gambar 11. Tema Anjungan Mengambil Keindahan Alam yang Terkenal

di Setiap Pulau Tersebut

Sumber: Penulis, 2021 


\section{Restoran Gastronomi}

restoran ini sendiri mengincar golongan kelas atas yang biasanya jarang mau mengenal budaya mereka sendiri, namun menghargai proses pembuatan makanan yang dibuat secara privat dan spesial untuk mereka. Maka narasi yang akan dibawakan oleh restoran ini adalah perjalanan bagaimana makanan ini sebagai wujud keseharian masyarakat, mulai proses pengolahan hingga penyajianya.

Akan ada beberapa sesi yang dapat tercipta, yang pertama adalah sesi "Storytelling" dimana akan penutup yang berisi dengan proyektor interaktif di dalamnya sebagai bagian dari interaksi, sekaligus edukasi. Kemudian pada sesi "diskusi/breaking" meja dapat diputar untuk sesi mengajak tamu antar meja untuk berinteraksi dengan makanan sebagai medianya.
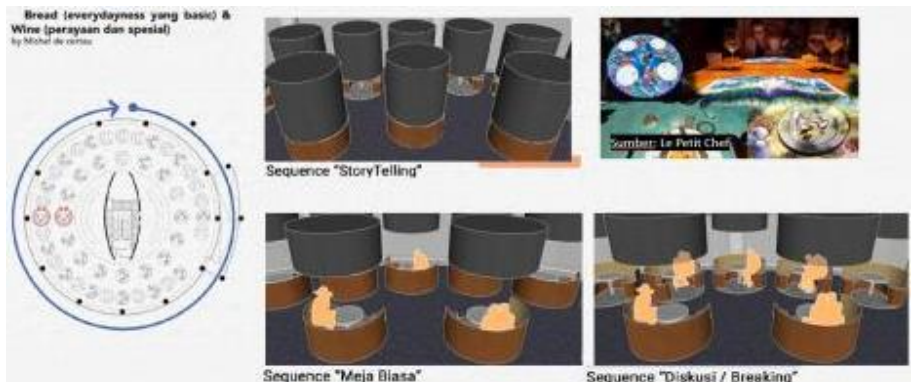

Gambar 12. Tema Anjungan Mengambil Keindahan Alam yang Terkenal di Setiap Pulau Tersebut Sumber: Penulis, 2021

\section{KESIMPULAN}

Living Museum yang menjadi wadah edukasi secara hidup yang mengenalkan praktek memasak, dan cara menikmati makanan sebagai bagian dari berbagai kebudayaan Indonesia yang heterogen secara interakti, melalui juru masak sebagai narasumber sudut pandang pertama. Proses memasak sebisa mungkin dapat terlihat oleh pengunjung, memungkinkan interaksi antar pengunjung dan juru masak dan observasi cara memasaknya, sebagai bagian dari pengenalan dan contoh pembelajaran kebudayaan dan sosial.

\section{REFERENSI}

Badan Pengawasan Keuangan dan Pembangunan. (1995). Peraturan Pemerintah (PP) tentang Pemeliharaan Dan Pemanfaatan Benda Cagar Budaya Di Museum. Jakarta.

Certeau, M. (1998). The Practice of Everyday Life Volume 2: Living \& Cooking. University of Minnesota Press.

Persagi 2020 , Mustika Rasa: Warisan Kuliner Nusantara dan Politik Pangan Nasional, diunduh 10 Maret 2020, dari https://www.persagibandung.org/2020/06/mustika-rasa-warisankuliner-nusantara.html

Rahman, F. (2018), Kuliner sebagai Identitas Keindonesiaan, Universitas Padjajaran, diunduh 10 Maret 2020, dari https://jurnal.masyarakatsejarawan.or.id

Rahman, F., Margana, S. (2014), Sejarah Makanan di Indonesia dalam Perspektif Global, Universitas Gajah Mada, diunduh 10 Maret 2020, dari

http://etd.repository.ugm.ac.id/home/detail pencarian/74573

Sutanto, A. (2020). Peta Metode Desain. Universitas Tarumanagara 